\section{Review: aspirin reduces the risk for stroke in patients with previous transient ischaemic attack or stroke but does not have a dose-response effect}

\author{
Johnson ES, Lanes SF, Wentworth CE 3d, et al. A metaregression analysis of the dose-response effect of aspirin on stroke. \\ Arch Intern Med 1999 Jun 14;159:1248-53.
}

\author{
QUESTION: In patients with a previous transient ischaemic attack (TIA) or stroke, does \\ a dose-response relation exist for aspirin use and the risk for stroke?
}

Source of funding: Boehringer Ingelheim.

For correspondence: $\mathrm{Mr}$ E S Johnson,

Epidemiology

Resources Inc. 1

Newton Executive Park, Newton Lower Falls, MA 02162, USA. FAX 617-244-9669.

\section{Data sources}

Studies were identified by searching Medline (to April 1996) and by scanning reference lists of relevant articles.

\section{Study selection}

Studies were selected if they were randomised, placebocontrolled, secondary prevention trials that included a comparison of aspirin alone and reported stroke as an outcome.

\section{Data extraction}

2 reviewers extracted published data on demographics, inclusion and exclusion criteria, treatment regimen, duration of follow-up, and all strokes (ischaemic and haemorrhagic). Another reviewer independently extracted data on outcomes, inclusion and exclusion criteria, and health status at entry.

\section{Main results}

11 randomised controlled trials met the selection criteria (9629 patients [5228 allocated to aspirin and 4401 to placebo], mean age $63 \mathrm{y}, 63 \%$ men, mean follow-up $32 \mathrm{mo}$ ). 1391 strokes occurred. Aspirin doses ranged from $50-1500 \mathrm{mg} /$ day. The combined results for all doses showed a benefit for aspirin in stroke (relative risk reduction $15 \%, 95 \%$ CI $6 \%$ to $23 \%$ ). Results were similar after adjustment for study and length of follow-up. A linear regression model showed that no linear dose-response relation $(\mathrm{p}>0.2)$ or quadratic doseresponse relation $(\mathrm{p}>0.2)$ existed for aspirin dose and the risk for stroke.

\section{Conclusions}

In patients with a previous transient ischaemic attack or stroke, aspirin reduces the risk for stroke. No doseresponse relation exists for aspirin doses between 50 and $1500 \mathrm{mg}$ /day and the risk for stroke.

\section{COMMENTARY}

The optimal dose of aspirin for prevention of stroke has been a long-standing controversy. Some neurologists believe that the most effective dose of aspirin to prevent stroke is higher than that for prevention of myocardial infarction. Although debated ad nauseum in recent years, the issue has risen again with the results of the European Stroke Prevention Study II, which showed that high-dose dipyridamole enhanced the protective effect of low-dose aspirin (ie, $25 \mathrm{mg}$ twice daily). ${ }^{1}$ This combination was recently approved by the US Food and Drug Administration (FDA) for secondary prevention of stroke and will be marketed soon by Boehringer Ingelheim (who sponsored this metaregression analysis by Johnson and colleagues). Whether the combination of high-dose dipyridamole and low-dose aspirin is considered superior to aspirin alone depends in large part on whether it is accepted that the dose of aspirin has no important effect on stroke prevention.

Johnson and colleagues report a sophisticated biostatistical analysis based on indirect comparison of the results of 11 randomised clinical trials, including the European Stroke Prevention Study II, and conclude that the protective effect of aspirin on stroke is uniform across aspirin doses from $50-1500 \mathrm{mg} /$ day. More convincing to me is the similar conclusion reached from considering the randomised clinical trials that directly compared aspirin doses ranging from $50-1200 \mathrm{mg} /$ day and, most recently, the Aspirin and Carotid Endarterectomy trial (81 v 325 v 650 v $1300 \mathrm{mg} / \mathrm{d}) .^{2}$ Although some have disputed the generalisability of the results of these direct randomised comparisons, ${ }^{3}{ }^{4}$ no persuasive evidence exists that higher doses of aspirin offer additional protection. In 1998, the FDA recommended aspirin doses between 50 and $325 \mathrm{mg}$ /day for secondary prevention of stroke.

For prevention of stroke in patients with TIA and previous ischaemic stroke, consensus on aspirin doses $\leqslant 325 \mathrm{mg} /$ day is emerging. Is aspirin alone the best available antiplatelet prophylaxis? Clopidogrel (congener of ticlopidine without its toxicity) and high-dose dipyridamole have also been shown to be efficacious (see the critical, balanced, recent reviews by Gorelick and colleagues ${ }^{5}$ and Wilterdink and Easton ${ }^{6}$ ). Aspirin remains the mainstay, but the era of combined antiplatelet treatments using aspirin with such agents as clopidogrel or dipyridamole for secondary prevention of stroke is on the near horizon, pending confirmatory evidence from ongoing clinical trials.

Robert Hart, MD

University of Texas Health Sciences Center, San Antonio, Texas, USA

1 Diener HC, Cunha L, Forbes C, et al. European Stroke Prevention Study. 2. Dipyridamole and acetylsalicylic acid in the secondary prevention of stroke.J Neurol Sci 1996;143:1-13.

2 Taylor DW, Barnett HJ, Haynes RB, et al. Low-dose and high-dose acetylsalicylic acid for patients undergoing carotid endarterectomy: a randomised controlled trial. ASA and Carotid Endarterectomy (ACE) Trial Collaborators. Lancet 1999;353:2179-84.

3 van Gijn J. Low doses of aspirin in stroke prevention. Lancet 1999;353:2172-3.

4 Hart RG, Harrison MJ. Aspirin wars: the optimal dose of aspirin to prevent stroke. Stroke 1996;27:585-7.

5 Gorelick PB, Born GV, D’Agostino RB, et al. Therapeutic benefit. Aspirin revisited in light of the introduction of clopidogrel. Stroke 1999;30:1716-21.

6 Wilterdink JL, Easton JD. Dipyridamole plus aspirin in cerebrovascular disease. Arch Neurol 1999;56:1087-92. 